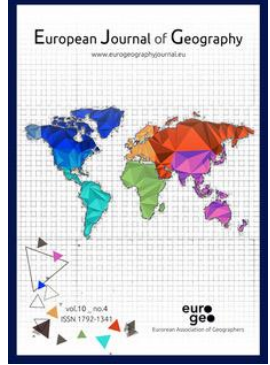

\title{
European Journal of Geography
}

Volume 11, Issue 4, pp. 064 - 092

Article Info:

Accepted: 16/12/2020

Corresponding Author: * giorglmbr@gmail.com https://doi.org/10.48088/ejg.g.lam.11.4.64.92

Special Issue: "Selected Papers from $12^{\text {th }}$ International Conference of the Hellenic Geographical Society (ICHGS): Innovative Geographies II, 2019"

\section{Perceived and lived space in the modern city. A case study for Akadimia Platonos neighborhood, Athens, Greece}

\author{
Georgios D. LAMPROPOULOS ${ }^{*}$, \\ Yorgos N. PHOTIS' ${ }^{1}$, Maria PIGAKI'
}

${ }^{1}$ National Technical University of Athens, Greece

\section{Keywords: \\ spatial practices, representational spaces, perceived space, lived space, space syntax, Akadimia Platonos, ICHGS-2019}

\begin{abstract}
The main objective of this paper is to perform a spatial analysis of everyday life experiences by enriching a socio-spatial approach within the boundaries of Akadimia Platonos neighborhood, in the city of Athens. It investigates the convergences and divergences that are observed between two different manifestations of space, as they have been approached through Henri Lefebure's social theory of space, the perceived space and the lived space. Mainly, the designed-geometric space, enhanced with all those relationships programmed for social reproduction, creates an experience for its users. Does this lived experience, that is expected to be experienced, actually correspond to reality? In the methodological framework proposed, perceived space (as spatial practices) is examined through the space syntax analysis of the study area, while lived space (as representational spaces) is accessed through questionnaire interviews, which examine the space perception of residents, workers, visitors, passers-by, using it.
\end{abstract}

\section{euro geo}

(c) Association of European Geographers

The publication of the European Journal of Geography (EJG) is based on the European Association of Geographers' goal to make European Geography a worldwide reference and standard. Thus, the scope of the EJG is to publish original and innovative papers that will substantially improve, in a theoretical, conceptual or empirical way the quality of research, learning, teaching and applying geography, as well as in promoting the significance of geography as a discipline. Submissions are encouraged to have a European dimension. The European Journal of Geography is a peer-reviewed open access journal and is published quarterly. 


\section{INTRODUCTION}

In modern cities, that are inhabited by millions of people, the multi-level transformations that have been identified in recent decades have been particularly intense, and their rates have clearly increased compared to the past. The geographical space of the city, the "picture" of it, as it could be prescribed in a treaty of the future, has most likely nothing to do with the past. However, one element remains, or at least should remain at the core of the existence of the cities, no matter which changes occur, and it is precisely what gives life to the concrete paradise: humans.

The current context of social transformation and urban changes increases the need for updated knowledge of living spaces (Zúñiga, Lopez, Gonzales, \& Campos, 2017). The living spaces of the cities should be examined and monitored so that any relevant transformation of the city would be orientated to the demands and needs of those who directly experience them - the residents.

The world -and cities as a basic element of it- is conceived by an extended eternity, rejected from direct vision. Therefore, the power of geography, which deals with the study of the earth's space, is now moving into the semantic area, which is proportional to the experiences and feelings of life (Sukhorukou \& Gladkiy, 2019). In such an approach, analyzing everyday life experiences, investigating the lived experiences of residents, employees, visitors, ordinary passers-by, located in suburban areas and neighborhoods, is of major importance. It is a fact that the space created by urban planners, designers, technocrats, by all those who are trying to structure the semantics according to which everyday social practices in the city should be understood, constitutes an experience for its users. Eventually, do the lived experience and the expected experience actually meet?

The purpose of this work is to create a methodological framework that examines the interaction between the community and the city itself, retrieving information on the perception and the actual experience of the users of a site, and explores the possibility of correlating the two. According to the proposed methodology, the perception (perceived space) and the experience (lived space) are first approximated. The perceived space is accessed by space syntax analysis of the site, while the lived space of the users is accessed using a questionnaire and direct contact with them.

\section{BACKGROUND}

French philosopher Henry Lefebure approaches perceived space and lived space, along with conceived space, as part of a tripartite dialectic, that structures a social theory of space. Constructing the theoretical lens through which we will approximate urban space, Lefebure argues that this is a homogenous space, regulated by the state and technocrats. However, from a practical point of view it is also a segmented space, as it is divided into pieces that are sold and bought, and theoretically, as its aspects are researched by different sciences leading to the hiding of its significance (Lefebure, 1974).

The segmented space corresponds to an equally segmented time, which can be in a way sold and bought. Working time, eating time, resting time, leisure time. Anyone who buys a space, also buys a specific use of time, based on the distances between the purchased-bought space and all the other spaces. The time which corresponds to a certain space is based, for example, on the distance between the working space and leisure or eating areas. These distances make some sites more desirable than others (Lefebure, 1977). 
Space for Lefebure is not a strictly defined "empty conteiner" where activities, social relationships and practices are established, as aduanced by some philosophical tendencies or by urban planners and social scientists as well. On the contrary, space is produced, changed, transformed by and, at the same time as it significantly determines through its previous stages of development, the activities taking place as well as the relationships and practices which are developing within it. Essentially, space constitutes a part of the later.

Space is not an object or a product among others. It integrates the objects produced by the activities and thus encompasses relationships and practices. It is the result of a sequence and a set of actions. It is thought of as a triadic dialectical relationship of concepts: spatial practices, representations of space, and representational spaces. This tripartite dialectic, as expressed by Lefebure, is an approach to a social theory of space, where each aspect coexists with the rest, and all together they constitute space (Lykogianni, 2011).

Hence a society's spatial practice "secretes" the space of this society. Inside the capitalist framework, it incorporates a close correlation within the perceived space, between daily reality (daily routine) and urban reality (the routes and networks connecting the places intended for work, "private" life and leisure) (Lefebure, 1974). Spatial practice concerns the material space and the usual spatial behaviors that someone can perceive. It examines physical and material flows, movements and associations in space, the reality of the city, and the routines of work, school, privacy, all of which ensure production, as well as social reproduction (Lykogianni, 2011).

The representations of space constitute the conceptual space. Hence the space of scientists, designers, planners, technocrats, of all those who define space, points, meanings, concepts and codes that allow us to better understand social practices. It is the space of those who determine, with a particular scientific inclination, what is lived and what is perceived based on what is conceived (Lefebure, 1974).

The term "representational spaces" refers to the lived space through representations or images and symbols, to the space of the "inhabitants" and "users", which is produced by the human body in everyday practice. At the same time, it is understood as a fantasy space, the space of artists and philosophers who describe it, or seek to describe it, through new visionary meanings and possibilities of socio-spatial practices (Lefebure, 1974). The lived space holds all those hidden secrets of the lived places that have to be explored by us (Hofmann, 2014).

\section{APPLICATION}

\subsection{Study area}

The area known as "Akadimia Platonos" (meaning "Plato's Academy") is located in the northwestern part of the modern city of Athens and administratively forms part of the Athens' municipality, where alongside with the western districts of Colonus, Votanikos, Profitis Daniil, Sepolia and Patisia, constitute the 4th district. At a span of 1,880 acres, the spatial unit of Akadimia Platonos has a strategic location on the Attica basin, as it is situated at the intersection of key national transport routes and at the same time just two kilometers from the historic center of Athens. It is bordered by Kifisou Avenue, Athinon Avenue, Lenorman Street and Konstantinoupoleos Street. Based on the 2011 
census by the Hellenic Statistical Authority (EL.STAT.) the total population of the region is 17,000 people.

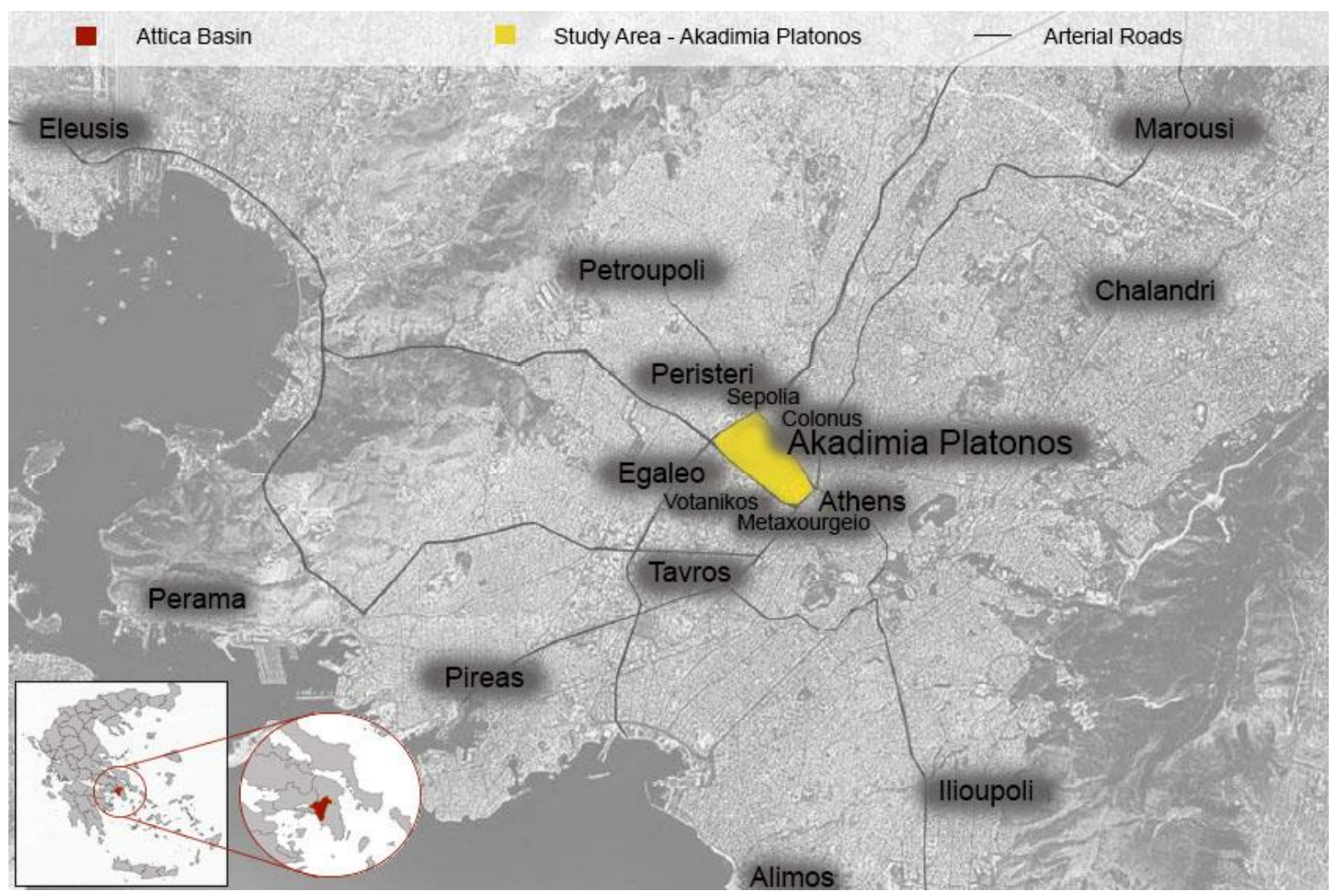

Figure 1 Akadimia Platonos neighborhood in the Attica basin

As Escudero says, the neighborhood is a territorial unit built, which is defined primarily social. That is, are the social aspects of its inhabitants and their interrelations, the "neighborhood life", which gives it character, but certainly the type of built space will also contribute to their identity (Escudero, 2017). According to this, the case study of Akadimia Platonos neighborhood as a spatial background was chosen because of its distinctive profile. The area has a variety of uses and forms, such as mixed-use housing, industrial parks and archaeological grove. Although nowadays this neighborhood of Athens is characterized by daily press and other mass media as "depleted" due to pollution from Kifisos (underground) river and air pollution from the heauy traffic, at the same time the untapped natural and cultural wealth, and the intense diffusion of functions (productive activities, housing and cultural uses) within the urban fabric, gives it an unexpected essence of life. 


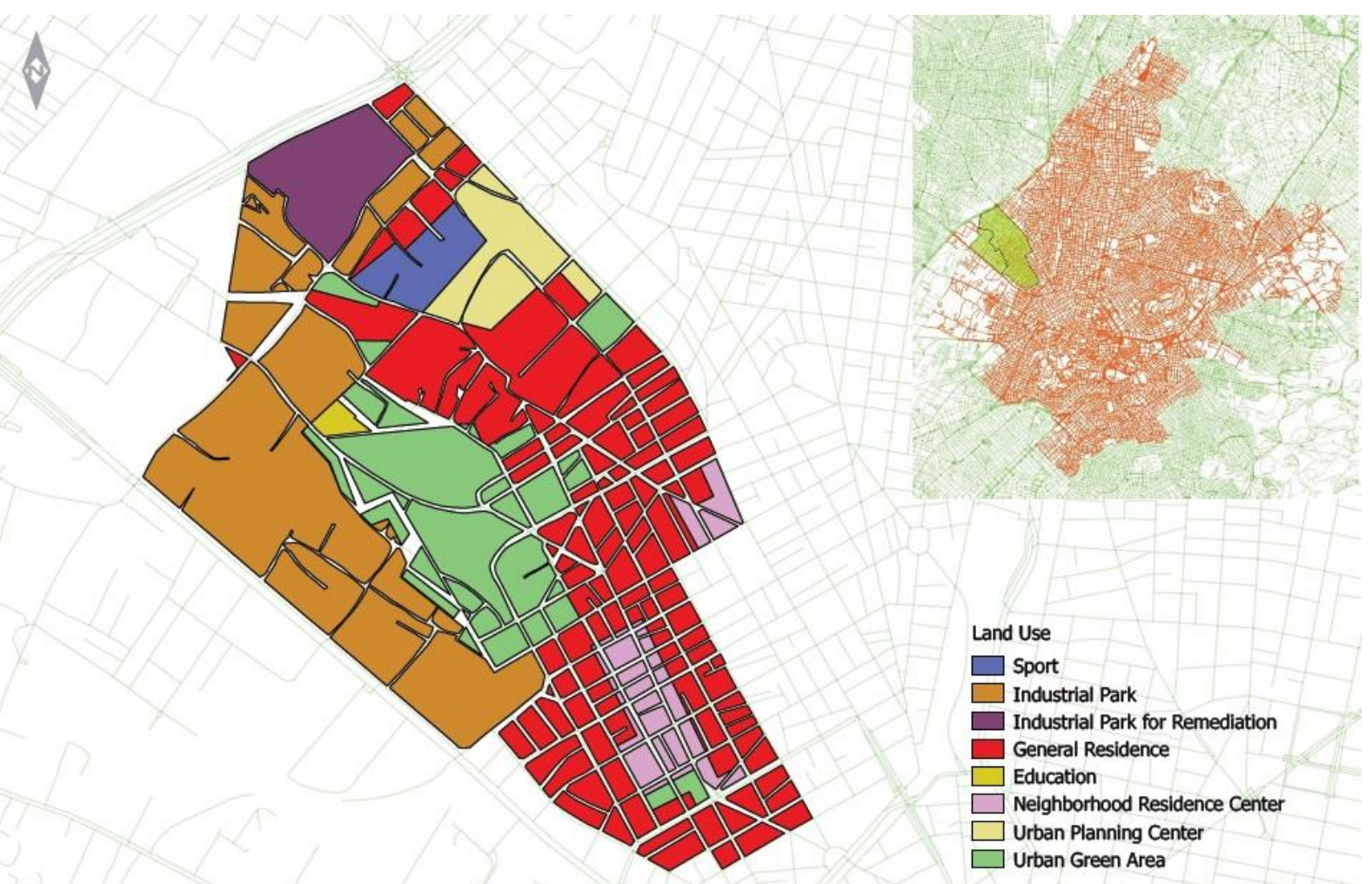

Figure 2 Land use in Akadimia Platonos neighborhood, QGIS software

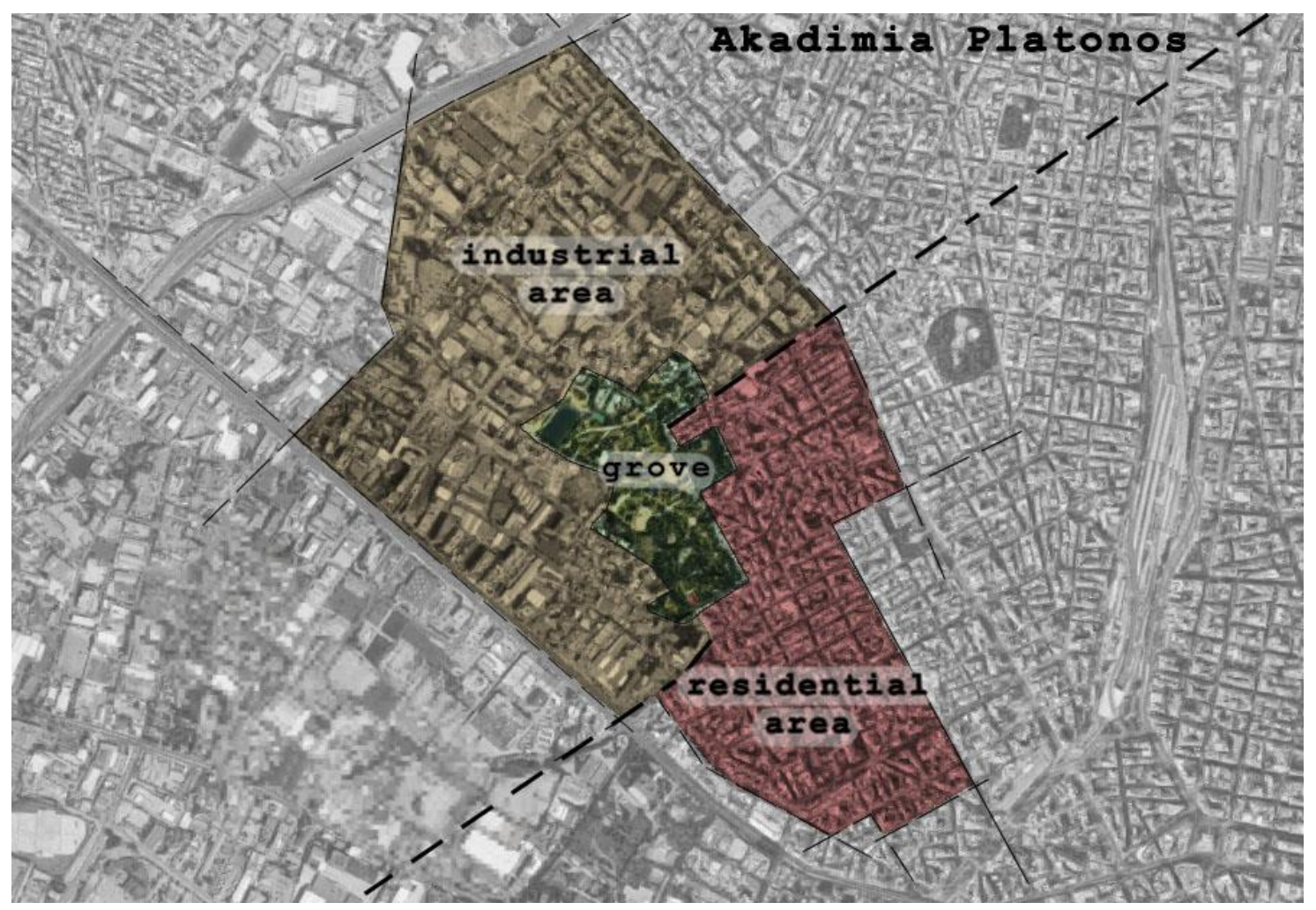

Figure 3 Sub-regions of Akadimia Platonos neighborhood, QGIS software 


\subsection{Perceived space, space syntax analysis}

Spatial practices, which incorporate a close correlation within the perceived space, between the daily routine and the routes and networks connecting the places intended for work, "private" life and leisure, were approached through a space syntax analysis of the area. The term space syntax is used to describe a set of theories and techniques concerning the relation between space and society that emerged from the research activity of a team led by Professor Bill Hillier at University College London (UCL) in the 1970s. Space syntax theory addresses the relationship between physical elements of a city (configuration), its social activity and the pattern of utilization (Czerkauer-Yamu \& Voigt, 2011). The main variable of urban form that is analyzed within space syntax is accessibility and how the accessibility between spaces varies according to the changes in the configuration of urban form (Marcus, 2007; Bartzokas-Tsiompras et al., 2021a).

Space Syntax research has put great effort into the development of representations and demonstrates a long series of descriptive techniques (Stauroulaki, Marcus, Berghauser Pont, \& Nilsson, 2017). Representing the city as networks, in this study a segment/vector analysis of the road network of the Akadimia Platonos neighborhood is carried out, in the sense that each section of the axial line between two intersections of the road network, constitutes the section of the maximum possible line of sight within the network (Vaughan, 2015). Specifically, angular segment analysis is used, based on the perception that the shortest path of the network is the one with the least angular deviation. Movement patterns have shown that humans do not move in space based on a conceptual model of metric distances, but on a geometric, angular model of the network (Hillier \& Vaughan, 2007).

At the same time, by analyzing the movement from all parts of the road network to others, according to the angular segment analysis, it is possible to predict the possible movement due to the architecture of the network itself as according to Hillier \& lida this particular method responds very well to navigation and orientation. Space users moving in an environment unfamiliar to them usually choose the shortest perceptible distance (Hillier \& lida, 2005).

The angular segment analysis measures used in the present study are those of choice and integration, which are calculated within a metric radius, which determines the network distance within which the angular deviation for each segment/vector of the road network is calculated. These measures are considered to be the most powerful tools for identifying possible movement and investigating important routes within an urban network (Al Sayed, 2014) (Vaughan, 2015).

Segment angular choice is calculated by counting the times that each segment of the road network is used in the shortest angular path between all pairs of segments within a selected distance (application's radius) (Vaughan, 2015). The choice expresses how likely a space to be used as a transit for the city is and ultimately quantifies the capability of passing-by of a space to the urban system to which it belongs.

Segment angular integration calculates how close to each other each segment of the road is, based on the total angular changes occurring in each path within a selected distance (application's radius) (Vaughan, 2015). In essence, integration expresses the closeness of a space to the system, or in other words, how easily it can be accessed. Ultimately, it quantifies the accessibility of a space relative to the urban system to which it belongs. 
The segment angular integration and choice measures apply to different radii, as mentioned above, which represent different scales of operation of the city. This enables analysis at different levels, reflecting local and global relationships emerging in the urban network. The applied radii of analysis' measures is a decisive factor which, as is understood, influences the results of the space syntax analysis and the decision of its value requires particular attention.

The local scale, typically one of local neighborhood structures in a city, is related to pedestrian traffic and is in the range of 200 - 800 meters, i.e. 5 to 20 minutes walking. The global scale that is representative of the structure of the city as a whole is related to vehicle traffic and refers to rays greater than 1500 meters.

Specifically, for the analysis of the Akadimia Platonos neighborhood six different application radii were selected, with values of 400,600, 800, 1500, 2500, 10000 meters. The selection was made to give special emphasis to pedestrian traffic $(400,600,800$ meters), while exploring both a mid-range (1500 meters) and a global scale (2500, 10,000 meters).

QGIS software (in particular the "Space Syntax Toolkit"), ArcGIS and DepthmapX were used to implement the space syntax analysis.

The "Space Syntax Toolkit" is a plug-in for QGIS software for spatial networks and statistical analysis. It provides a front-end connection for the DepthmapX software within QGIS, providing user-friendly workflows for implementing space syntax analysis in Geographic Information Systems (GIS) environment (originally developed by Jorge Gil at Space Syntax Laboratory, Bartlett School of Architecture, UCL in 2014) (UCL Space Group, 2016).

DepthmapX is an open source multi-platform software which runs a series of spatial network analyzes designed to understand social processes within the built environment. It operates on a variety of scales, such as buildings and small urban networks but even on whole cities and states. At every scale, the software's goal is to produce an open space elements' map, linking them through a relationship (for example, mutual visibility or overlap), and then perform graph analysis of the resulting network (Varoudis, 2012).

\subsubsection{Construction of axial/segment map}

While being analyzed with the syntactic structure model, the urban network is represented by visibility lines created within it. It is defined by points and objects that block movement (e.g. islets) and ultimately restrict access. Because of this and in order to apply the space syntax analysis, an axial map should be drawn where the axial lines resemble the visibility lines.

For the production of the axial map, the neighborhood's road network (data from Open Street Map) was initially used in the form of road center lines. The network was simplified by using the simplify geometries command of QGIS geometry tools and the initial network topology was corrected by using the u.clean toolbar (snap tool for connectivity, break tool for correcting the topology of the necessary nodes). Subsequently, using the RCL Topology Cleaner tool of the "Space Syntax Toolkit", further topological errors of the road axis map were "cleaned", and then loading the map to ArcGIS software, using the command erase of the overlay toolbox of the analysis tools, a spatial erase of the duplicate network recordings was performed. A final manual correction of the already "cleaned" network followed, checking the axes that were 
marked as errors and inserting/digitizing axes so that the final network was complete and correct in terms of connectivity and topology. The errors that are detected fall into three categories:

- Duplicate geometries: Two lines with identical geometry.

- Orphans: Lines not intersect with any other line.

- Continuous lines: Lines which due to their length and/or geometry (e.g. many turns) cannot form lines of sight and therefore axial lines.

Finally, the network topology and connectivity verification was performed with the use of the verify command of the Graph Analysis tool of the "Space Syntax Toolkit" (after each error correction was performed again). The categories of errors found during verification fall into the following categories:

- Duplicate: Two lines with identical geometry.

- Orphans: Lines not intersect with any other line.

- Island: A group of lines that is disconnected from the main map.

- Polylines: Lines consisting of more than two nodes.

- Small lines: Lines less than minimum (default $1 \mathrm{~m}$ ).

- Short lines: Lines whose endpoint is close to other lines without intersecting (default $1 \mathrm{~m})$.

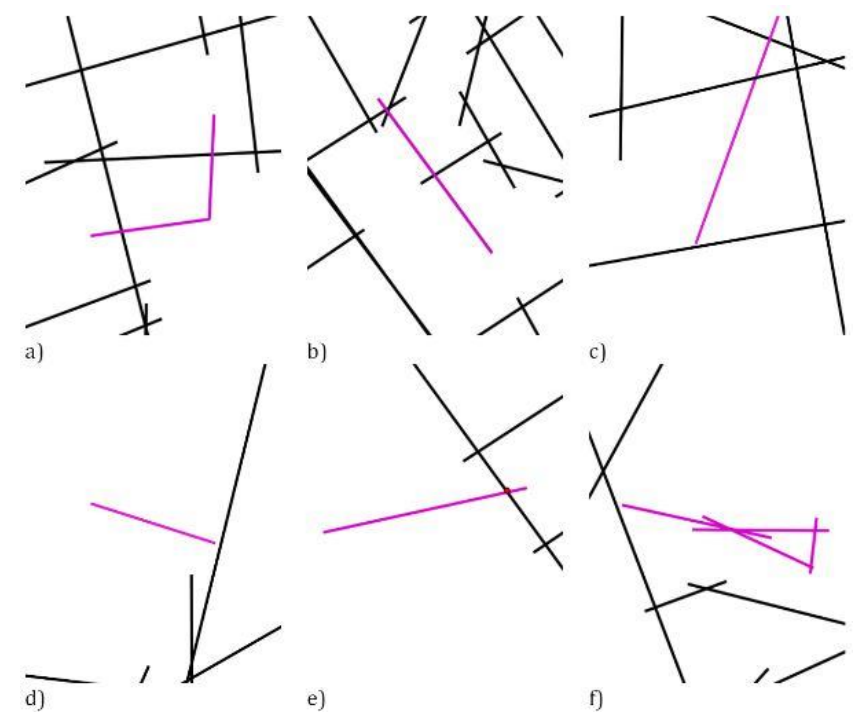

Figure 4 Errors occured during verification a.Polyline, b.Duplicate, c.Short, d.Orphan, e.Unlinked orphan, f.Island (Gil, 2015)

After the network has been corrected and verified, the generated axial map is segmented to convert the axes into road segments/vectors and be possible to perform the segment analysis. 
Figure 5 The produced segment map within the boundaries of the Akadimia Platonos neighborhood, QGIS software

\subsubsection{Space Syntax Analysis}

Subsequently, the analysis of the syntactic structure model of the Akadimia Platonos neighborhood in the QGIS environment was applied. The Graph Analysis tool of the "Space Syntax Toolkit" was used for the application. At this point it was necessary to use DepthmapX software, which only needed to be running in the background as the "Space Syntax Toolkit" offered a front-end connection to it. Specifically, through the depthmapX remote tab and the selection of segment analysis (instead of simple axial analysis), once the radius of application was defined, the space syntax analysis measures for the study area were calculated.

The space syntax analysis' measures calculated, as mentioned above, are integration and choice of radius in a scale of 400,600, 800, 1500, 2500, 10000 meters. The calculated measures were visualized using the Attributes Explorer tool of the "Space Syntax Toolkit". The results are presented below in series of maps. 


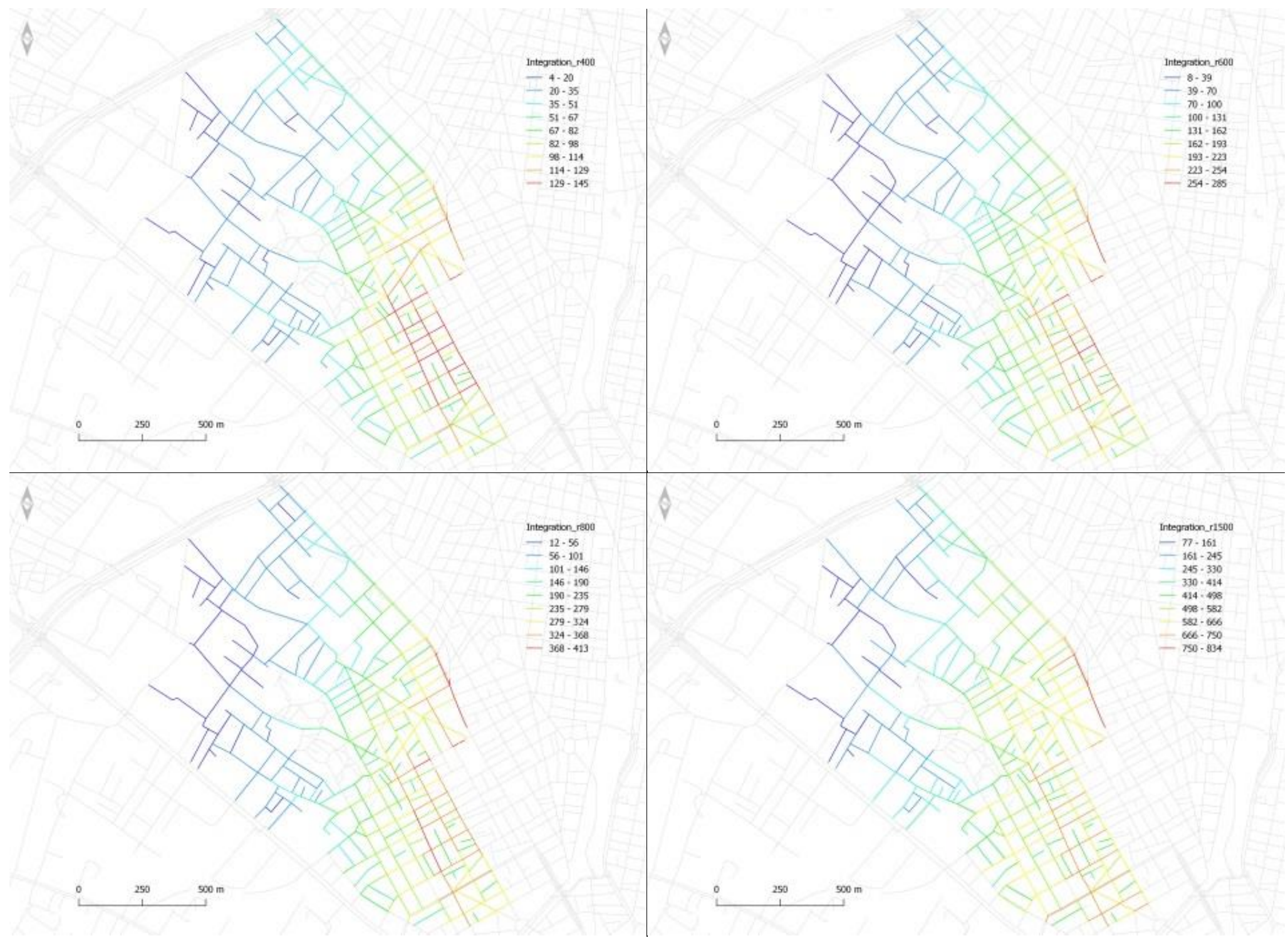


$\hat{P}$
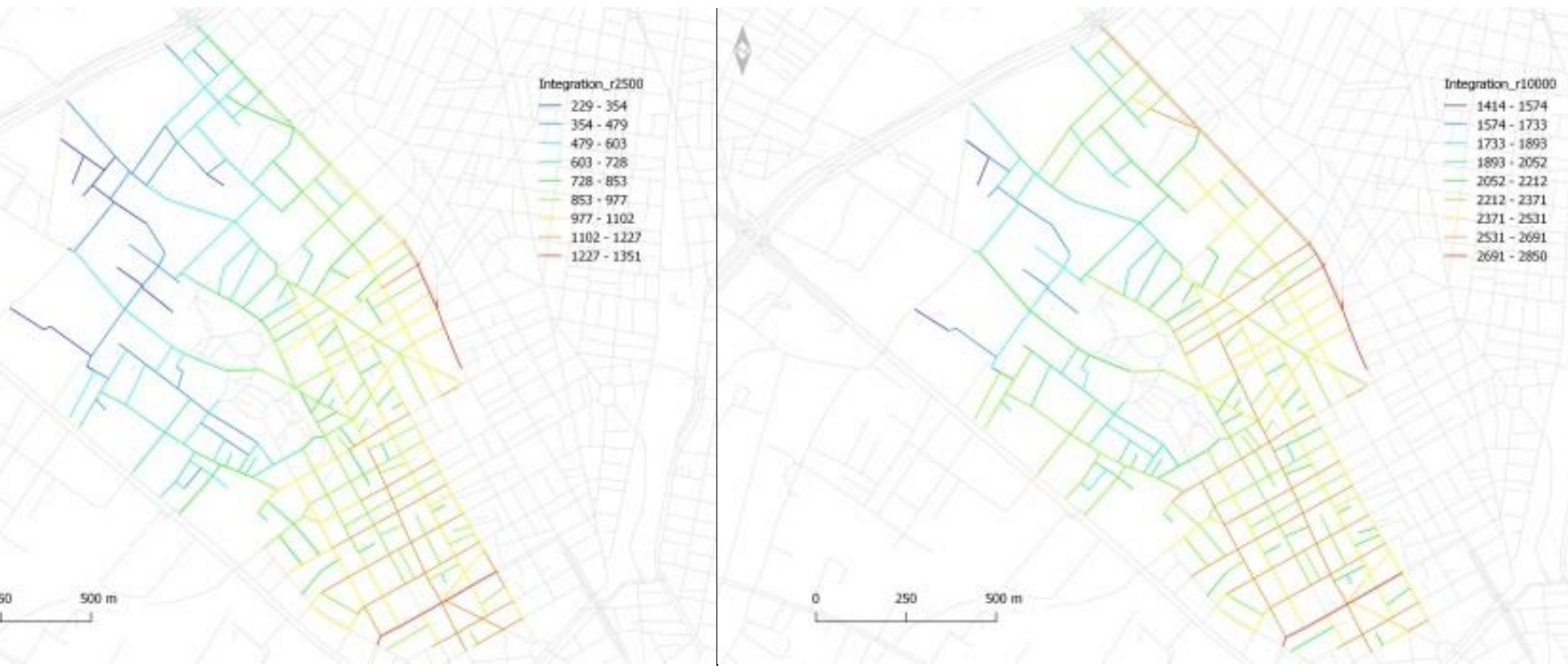

Figure 6 Space syntax analysis' results of Akadimia Platonos neighborhood, measures: integration, radii: $400,600,800,1500,2500,10000$ meters, QGIS software
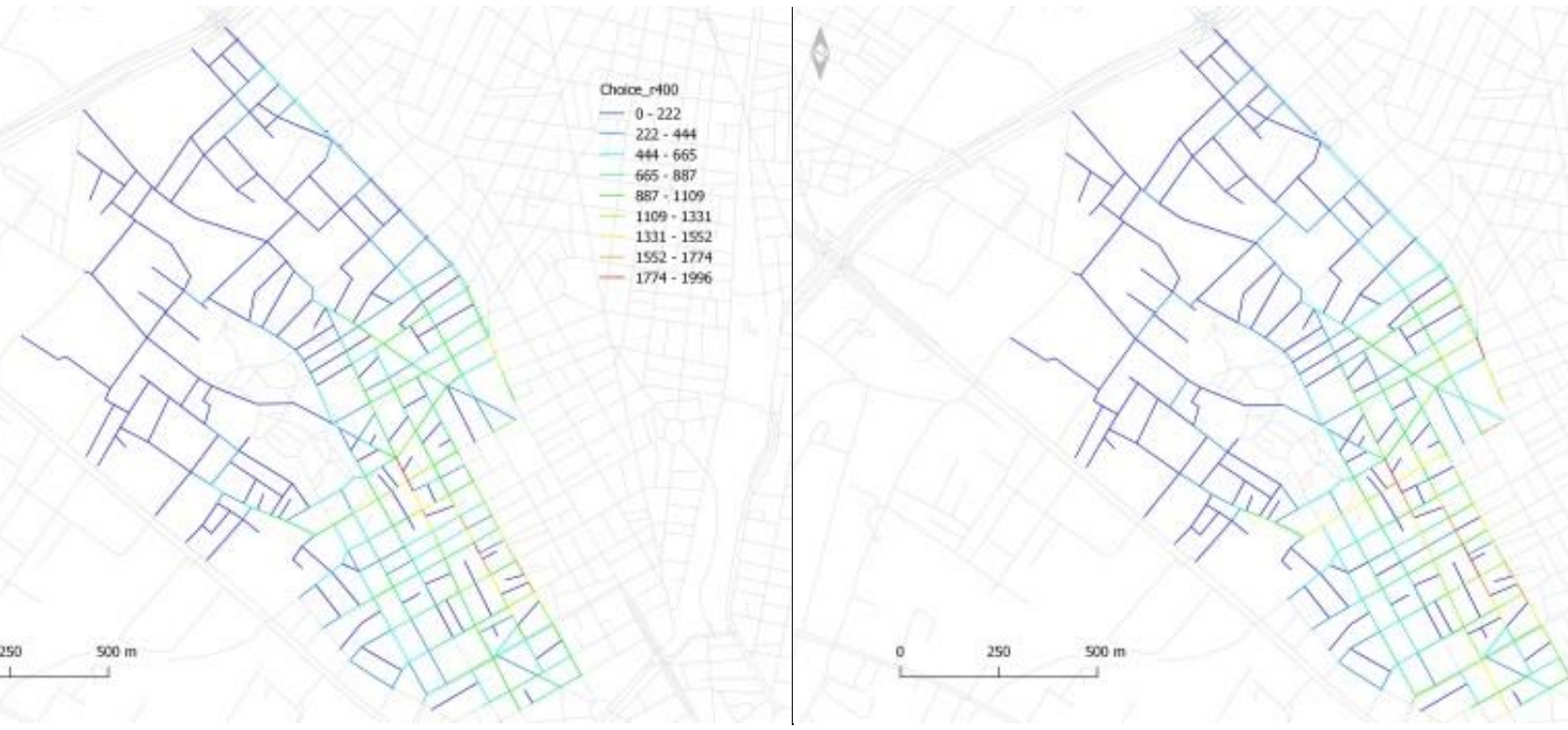


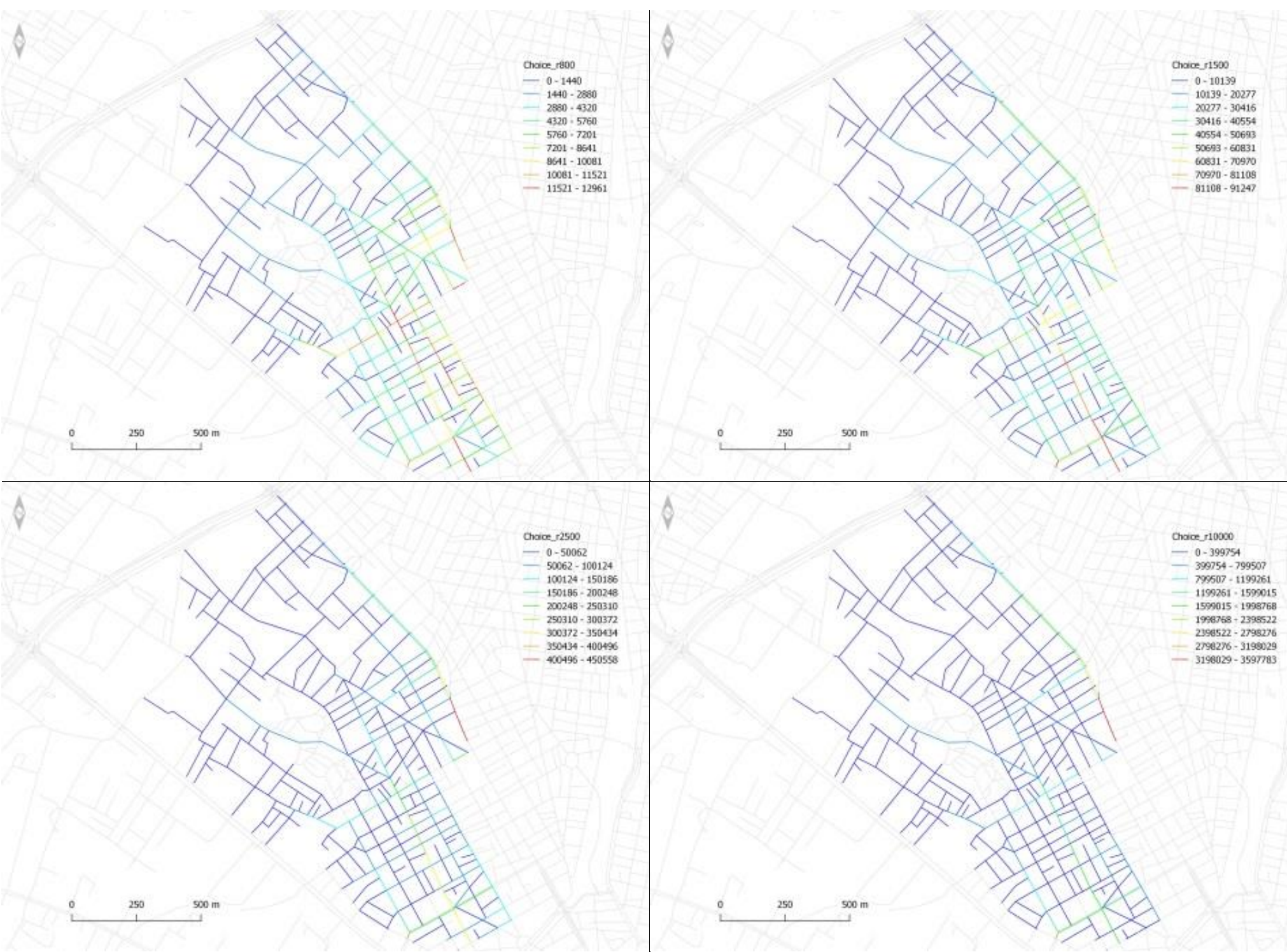

Figure 7 Space syntax analysis' results of Akadimia Platonos neighborhood, measures: choice, radii: 400, $600,800,1500,2500,10000$ meters, QGIS software

\subsection{Representational spaces, spatial analysis of lived space}

Questionnaires were used in order to understand and analyze the representational spaces, the lived space, the space of the inhabitants as they understand it, the space produced by the body through everyday practices. The questionnaire includes openended and closed-ended questions, fill-in questions, multiple-choice questions and questions on a calibrated scale. The sequence of questions was structured in a way to explore the more general experience of existence and the place satisfaction (Mohammed, 2011). In general, the questions that users are asked to answer reflect a series of different manifestations of space such as socio-communal, sensory experience and functional. More specific, the neighborhood features of the area, individual-collective memory retention, accessibility, walkability, abandonment, sensory qualities of olfactory and acoustic stimuli, the corresponding nuisance they cause, and the level of appropriation they are experiencing, are examined, both for the exact point where the respondent fills 
out the questionnaire and for the whole district. Three hundred questionnaire forms were collected.

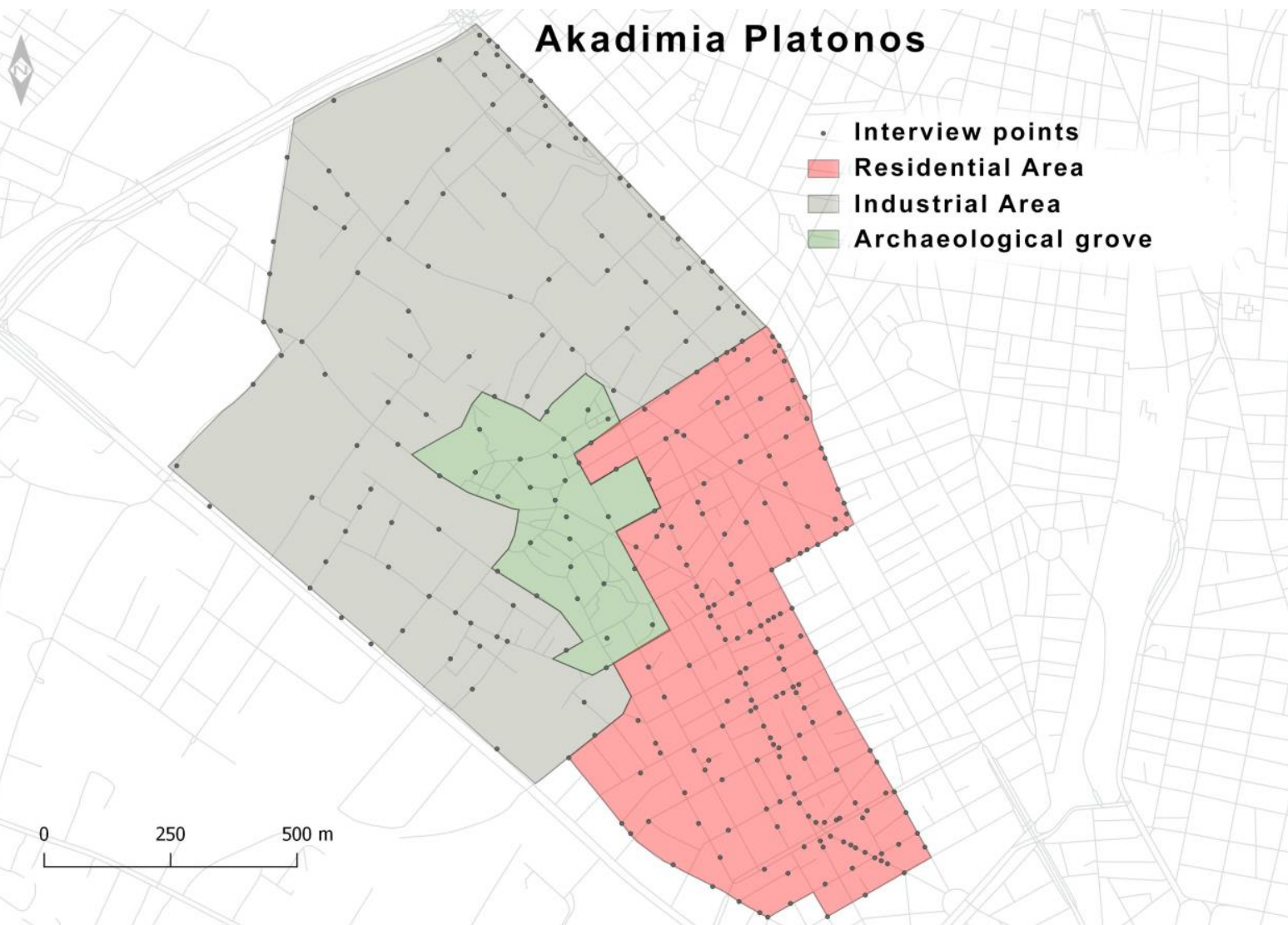

Figure 8 Interview points in Akadimia Platonos neighborhood, QGIS software

\subsubsection{Spatial interpolation}

For the analysis and mapping of the results of the questionnaire survey, a spatial interpolation was used to convert the point information collected into continuous and to create thematic maps that depict the change of the parameters under study in the field.

Spatial interpolation is based on the First Law of Geography, formulated by Geography professor Waldo Tobler in 1970, and states that everything is related to everything else, but the observations that are closer to each other are more relevant than those that are in distance (Longley, Goodchild, Maguire \& Rhind, 2005). The term spatial interpolation generally refers to the process of determining the value of a variable $z$ at some point $(x, y)$ in space, since the values of this variable at a set of points -which are usually randomly distributed in space- are known. Based on spatial interpolation methods, the initial fragment information enclosing the starting points for the parameter in question is converted into continuous information which is represented by a continuous surface.

Various algorithms have been developed over time and categorized in a variety of ways. The inverse distance weighted interpolation method (IDW) was chosen for the specific research performed in the present study. The basic principle of the IDW method 
is that when calculating a value at a particular point in space, more emphasis is placed on values corresponding to its neighboring starting points than on the most distant ones. The general relation underlying the method is the following,

$$
f(x, y)=\frac{\sum_{i=1}^{n} w\left(d_{i}\right) \cdot z_{i}}{\sum_{i=1}^{n} w\left(d_{i}\right)}
$$

where $f(x, y)$ is the simulated value of the parameter in question at point $(x, y), w\left(d_{i}\right)$ the weight function, $z_{i}$ is the measured value of the parameter at point $i, d_{i}$ the distance of point $i$ from point $(x, y)$.

The continuous surface resulting from the application of this interpolation method depends directly on the weight function used. The weight function can take many forms, but it is essential to apply $d 0, w\left(d_{i}\right)$. Functions that satisfy this assumption are of the form $d^{-r}(r>0), \exp (-a d)$ or $\exp \left(-a d^{2}\right)$ and so on. The most commonly used are the functions of the form $d^{-r}(r>0)$, where as much as the value of $r$ increases, the more weight is given to the nearest starting points, where the interpolation will occur. As a result, the method is applying in a more local scale and consequently the resulting surface is more detailed and less smooth. The weight function used to create the continuous surface in this case and the most commonly used one is $\mathrm{d}^{-2}$, which has been estimated as the most effective (Kitsiou, 2010).

The value of any point resulting from the interpolation applies to the relation $\min \left(z_{i}\right) f(x, y) \max \left(z_{i}\right)$, since $w\left(d_{i}\right)>0$. This is considered a disaduantage of the method because the resulting surface cannot accurately predict the positions and sizes of the maximum and minimum values unless they are included in the original samples. In the research conducted for the present study, the extreme values of the observations are included in the original sample, which makes this method suitable for analyzing the questionnaire data.

\subsubsection{Questionnaire data}

At the beginning of the questionnaire, general questions about the respondent's gender, age, relationship with the area (selection between: resident, employee, passer-by, visitor) and duration of this relationship are encountered. Regarding the results of this part of the questionnaire, 59\% of the respondents were male (178 people), while $41 \%$ were female (122 people), 82 people were young, up to 30 years (27\%), 131 people were between the ages of 30 and 50 years old (44\%), while 87 people were older than 50 years old $(29 \%)$.

Most of the respondents were residents (162 people, 54\%) or employees (109 people, $37 \%$ ) in the area, while very few were passers-by (16 people, $5 \%$ ) and visitors (13 people, 4\%).

Regarding the time period that the respondents have been in the neighborhood, results vary as expected. Details are shown in the diagram below. 


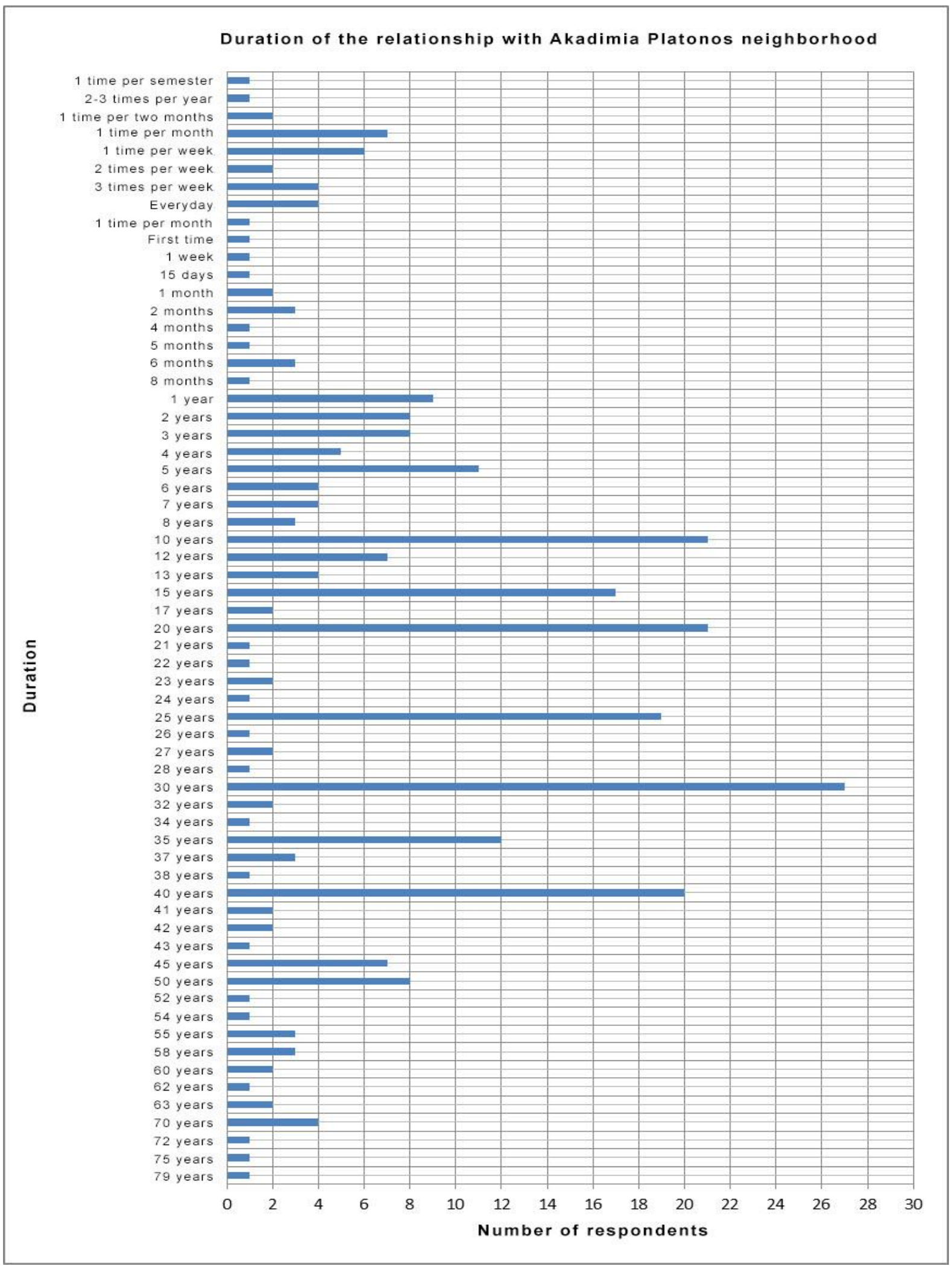

Figure 9 Duration of respondents' relationship with the district

Looking at the duration of the relationship with the study area, it is observed that the strongest majority of people who responded to the questionnaire are people who have lived or worked in the area for more than 10 years (206 people). This figure, together 
with the percentages for respondents' relationship with the Akadimia Platonos neighborhood ( $91 \%$ were residents or employees) substantially substantiate what was mentioned on the study of the area's physiognomy. We are referring to a neighborhood dominated by residential use alongside with small manufacturing and other local businesses, while entertainment centers and department stores, attractions for neighborhood's non-native people, are disappearing. So, it is understood that the responses to the interview concerning the area of the neighborhood come from people who, for the most part, have been in the area for several years and consider this place as "home" or "second home", as is customary to refer to workplaces, carry at least to some degree an in-depth view of the area having developed, whether they wish it or not, a subtle attachment to it. The following are thematic maps sawing the alteration of the questionnaire parameters in space using the IDW spatial interpolation method. The color gradation of the created surface from blue to red, as shown in the legend, indicates the intensity of the phenomenon. 

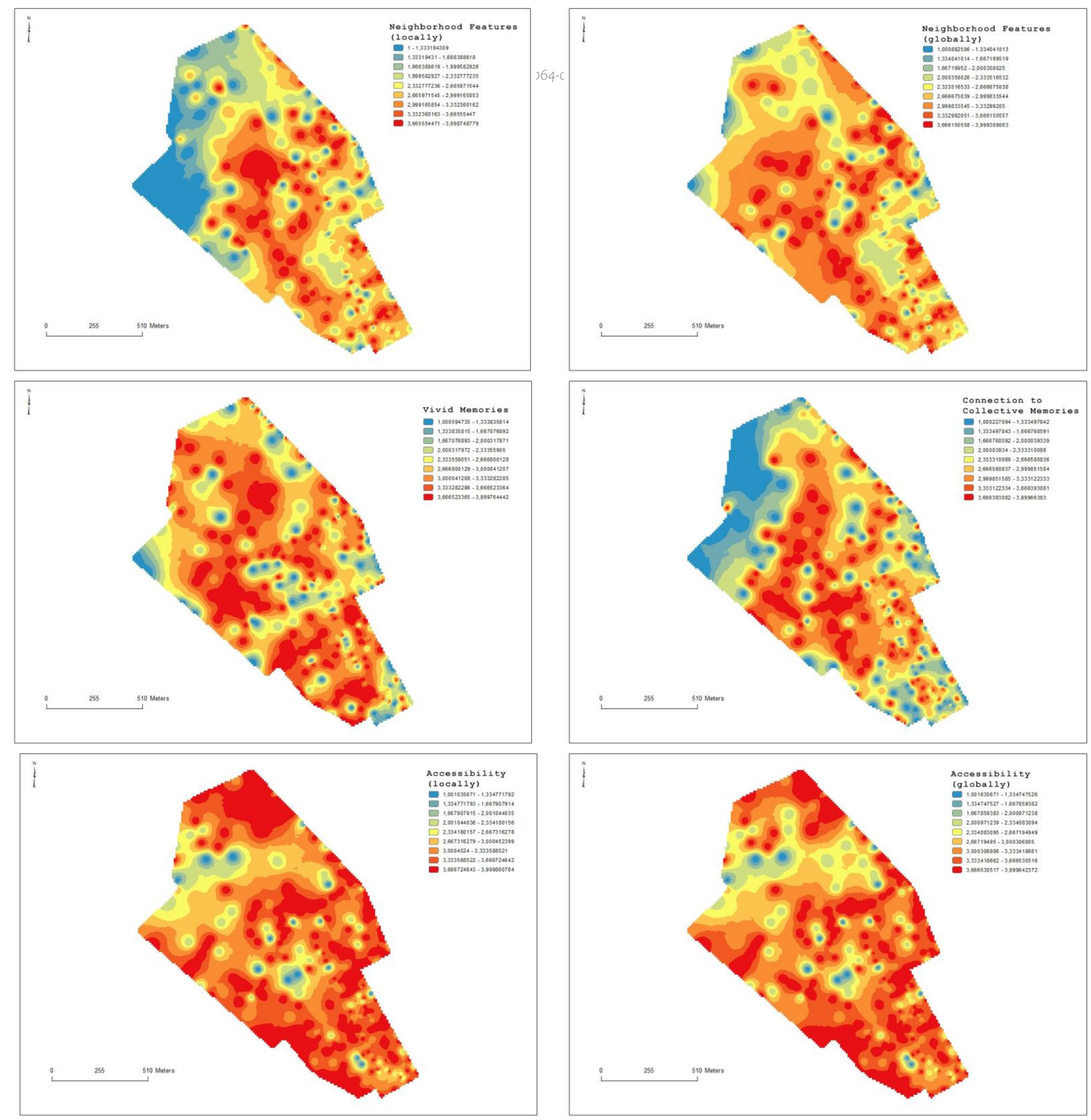

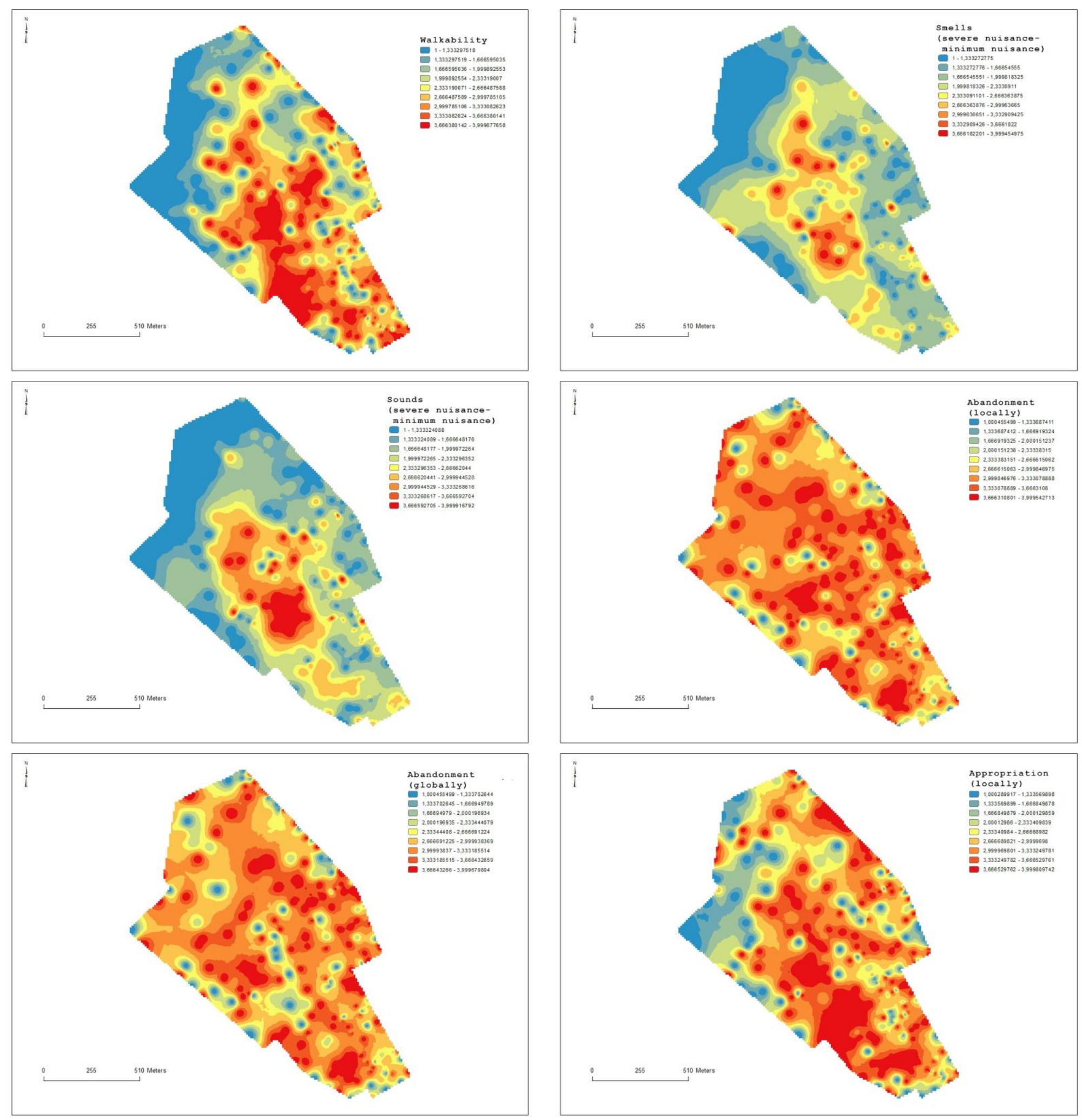


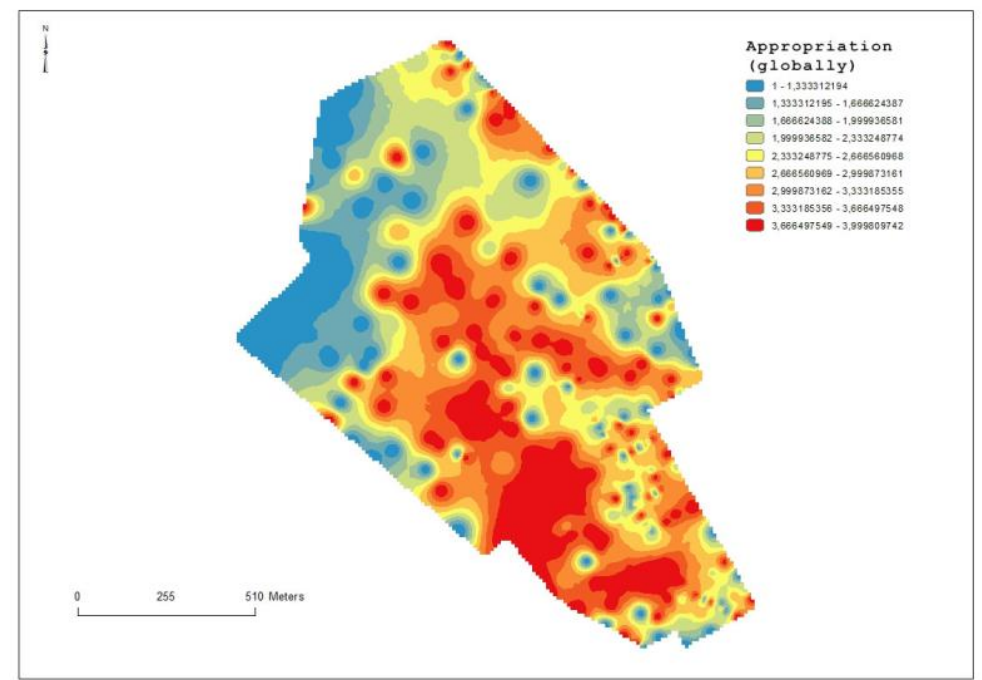

Figure 10 Thematic maps showing the alteration of the questionnaire parameters in space, using the IDW spatial interpolation method, ArcGIS software

\subsection{Convergences and divergences of perceived and lived space}

\subsubsection{Methodological framework}

The proposed methodological framework puts at its core the preparation of data sets produced by the analysis of the neighborhood's syntactic structure model and those collected from the questionnaires, in order to investigate their relevance. Both the data from the space syntax analysis and the questionnaire categorical data followed a similar procedure.

Initially, the Kernel Density Estimation (KDE) method was applied with the aim of creating a raster surface for the whole neighborhood, where each point would receive a value proportional to the distance from the originally produced / collected data. The procedure was performed in ArcGIS software using the Kernel Density tool of the Spatial Analyst toolbar, which calculates the density of attributes in a neighborhood around them. It calculates a value per area unit of each point or line using the spatial interpolation method. The surface value is higher at the point and decreases to zero by increasing distance. In general, in Geographic Information Systems (GIS), the result of a Kernel Density process is a set of raster data (Longley, Goodchild, Maguire, \& Rhind, 2005), where each cell has a density value that is weighted by the distance from initial features. The user can select the cell size, the attribute field to be used for the calculation, the units of measure and the application radius of the algorithm (De Smith, Goodchild, \& Longley, 2007). Finally, the result of the process is the representation of the density of the attributes as a continuous field where for each point (cell) the value of the attribute density estimation generated by the features located inside the application radius of the algorithm.

Then, in order to integrate the values of the previously created continuous cell in a scale between 0 and 1, a linear membership function was implemented in ArcGIS software through the Fuzzy Membership tool of the Spatial Analyst toolbar. The Fuzzy Membership tool re-sorts / converts input data on a scale of 0 to 1 based on the probability of being 
members of a specified data set. 0 corresponds to those positions which are certainly not members of the specified set, while 1 is assigned to those which definitely are. The entire range of values between 0 and 1 is probably assigned to all other positions (the greater the number, the greater the probability). Specifically, it applies the Fuzzy Linear Membership function which linearly transforms the input values on a scale of 0 to 1 , with 0 corresponding to the lowest input value and 1 to the highest input value. All intermediate values receive some entry value on a linear scale, with higher input values more likely to be closer to 1 (desktop.arcgis, 2016).

Finally, for the processing of data on the scale of 0 to 1 that raster surface's cells have obtained, spatial information on the city blocks was used in ArcGIS software, which functioned as the zones in which the cell values were derived. Spatial Analyst's Zonal Statistics as Table tool was used, which calculates statistical values within a given zone (building blocks) based on the values of another dataset (the previously created raster surface). This tool was used precisely because it renders the results in a table and not on a new raster surface (desktop.arcgis, 2016). The input zones layer defines the shape, values and positions of the zones, while the raster input surface essentially provides the input values used to calculate the output statistical values for each zone.

From the generated tables it was chosen to maintain the MEAN column, which gives each zone the average value of the raster surface cells within its boundaries, and to be the one that will be the set of data to be correlated for each variable.

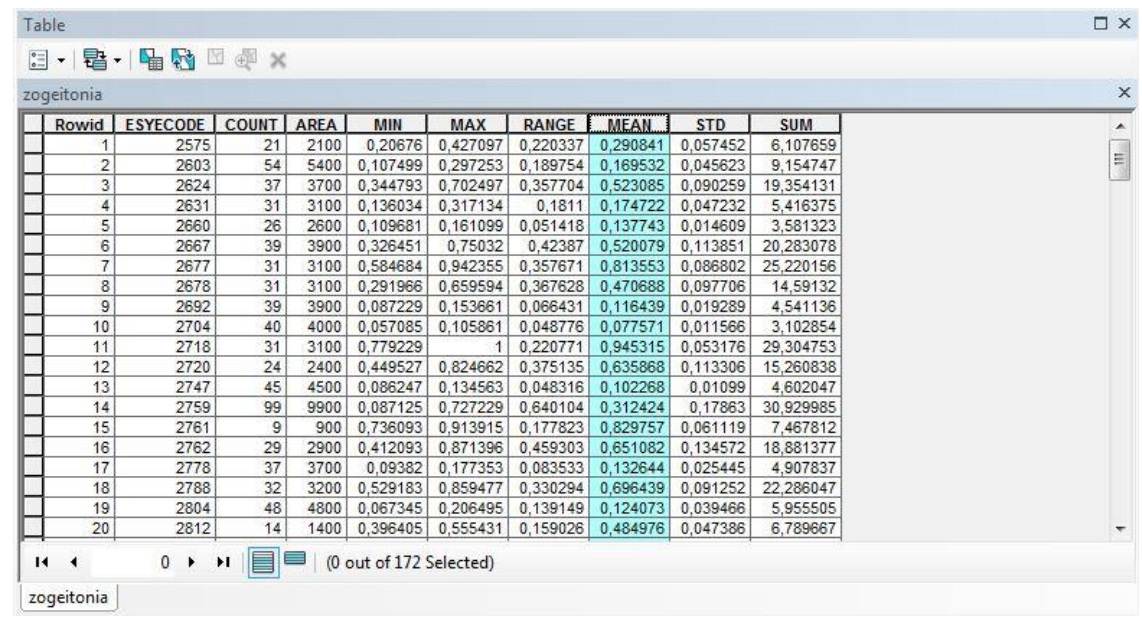

Figure 11 Table produced using Zonal Statistics as Table tool, neighborhood features, ArcGIS software

Following the above forementioned procedure, a value is assigned to each of the variables we want to test for their correlation in each of the 172 building blocks of Akadimia Platonos neighborhood.

The variables mentioned are the two measures of the space syntax analysis of the study area: integration and choice, for each application radius (int400, int600, int800, int1500, int2500, int10000, ch400, ch600, ch800, ch1500, ch2500, ch10000), as well as each of the questionnaire items (neighborhood (locally), neighborhood (globally), memories, collective memories, accessibility (locally), accessibility (globally), walkability (Bartzokas-Tsiompras \& Photis, 2017; Bartzokas-Tsiompras et al., 2021b), sounds, smells, abandonment (locally), abandonment (globally), appropriation (locally), appropriation (globally)). 

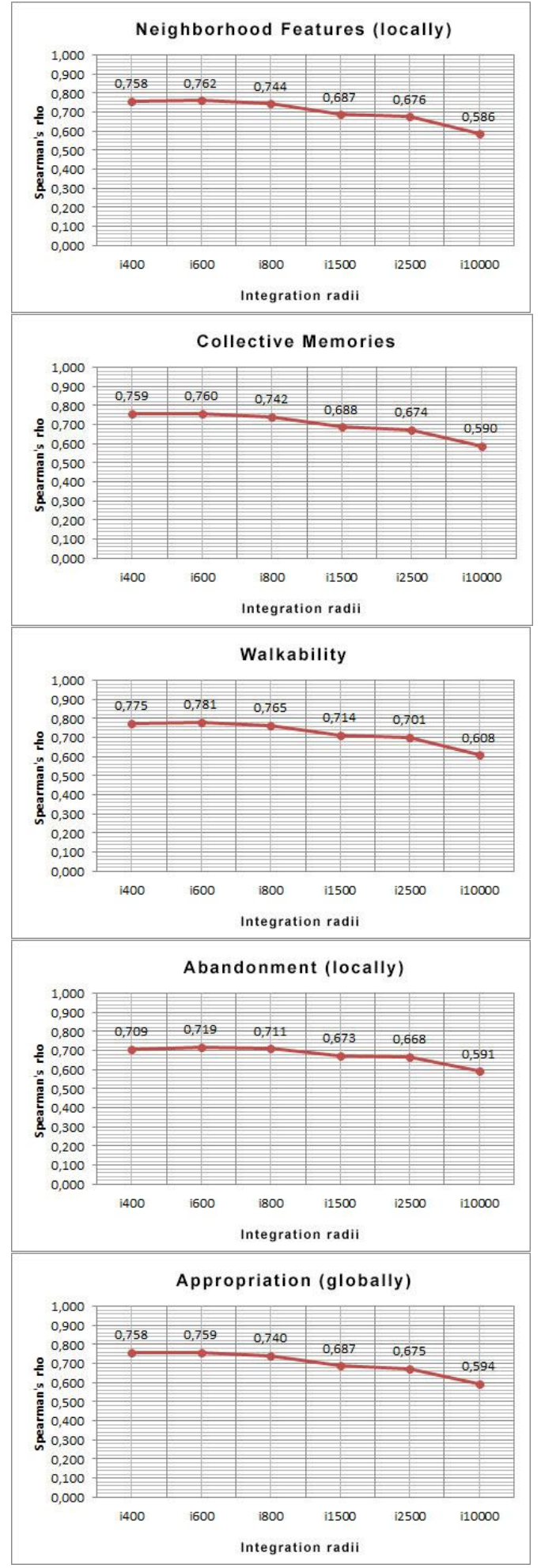
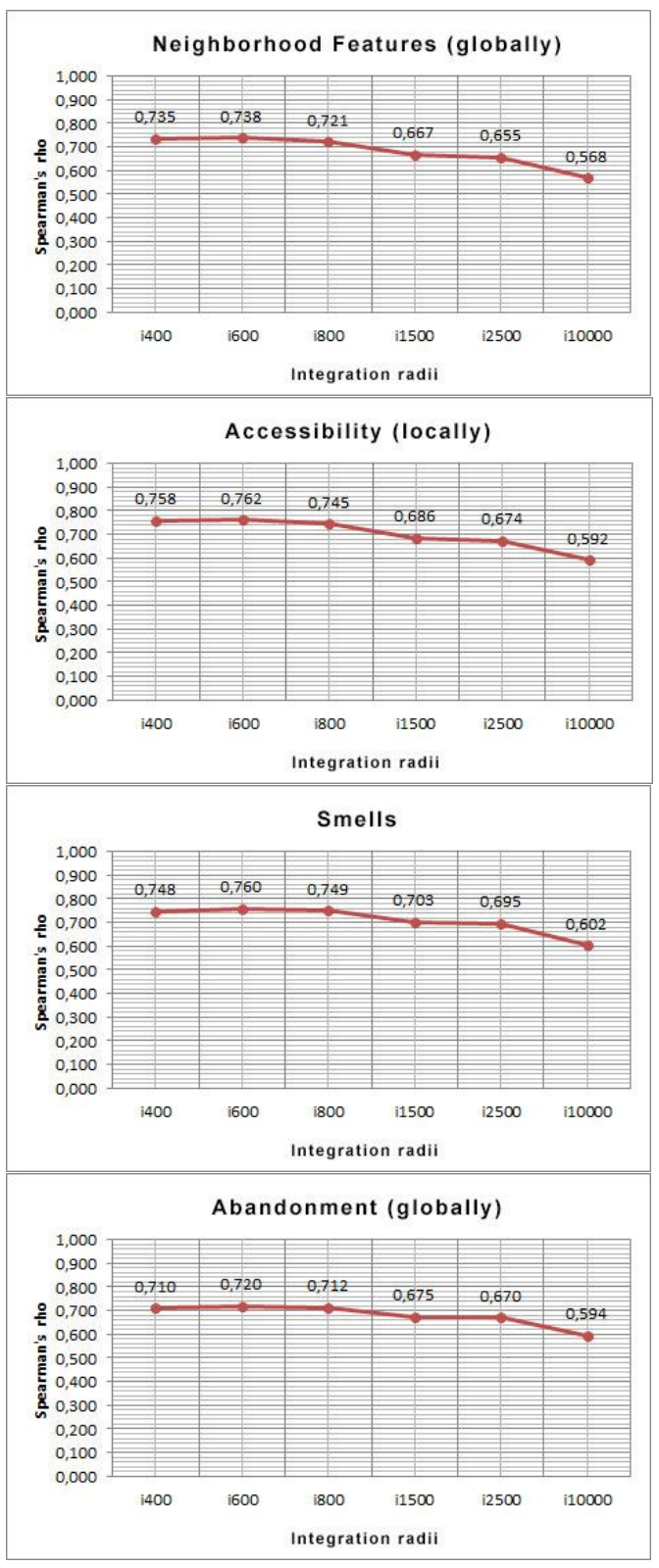
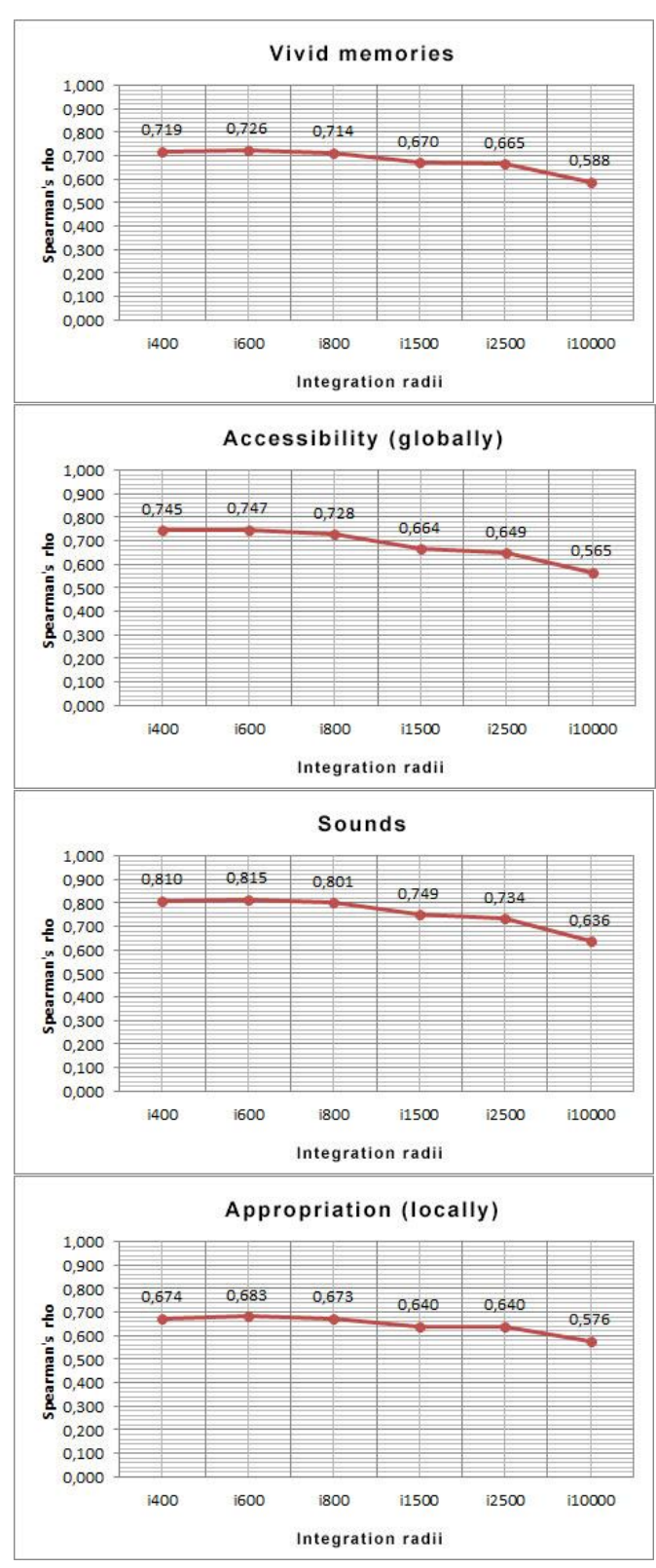

Figure 13 Results, Spearman's correlation coeficient, questionnaire variables - integration measure for different application radii 

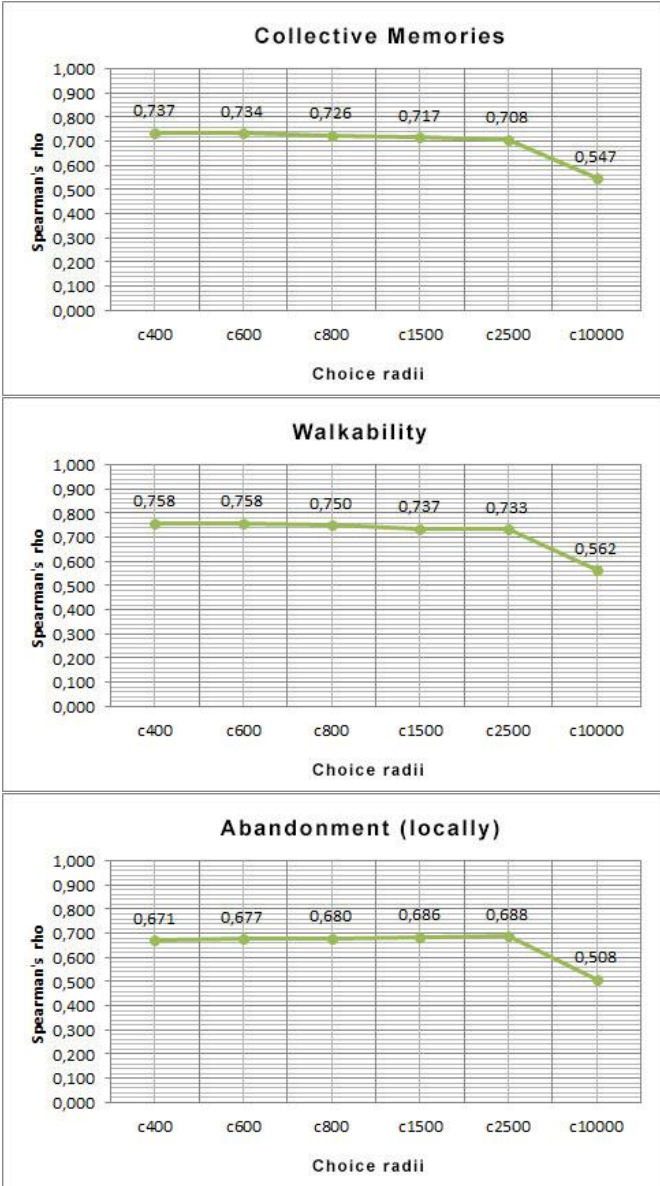

Appropriation (globally)

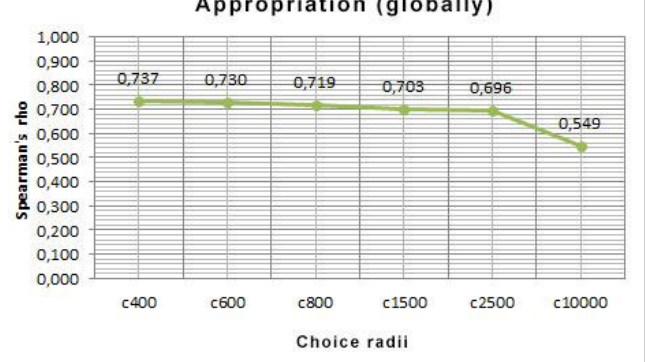

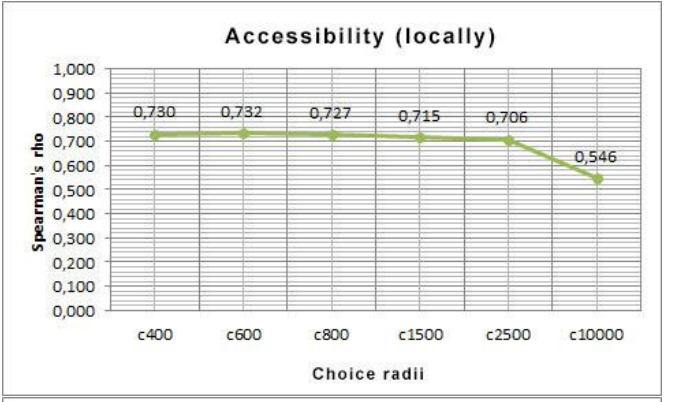
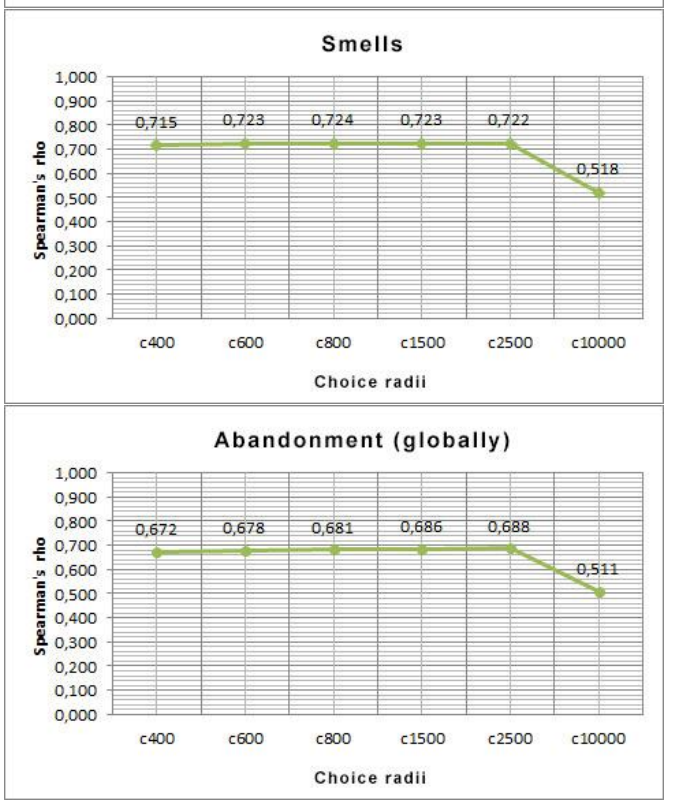
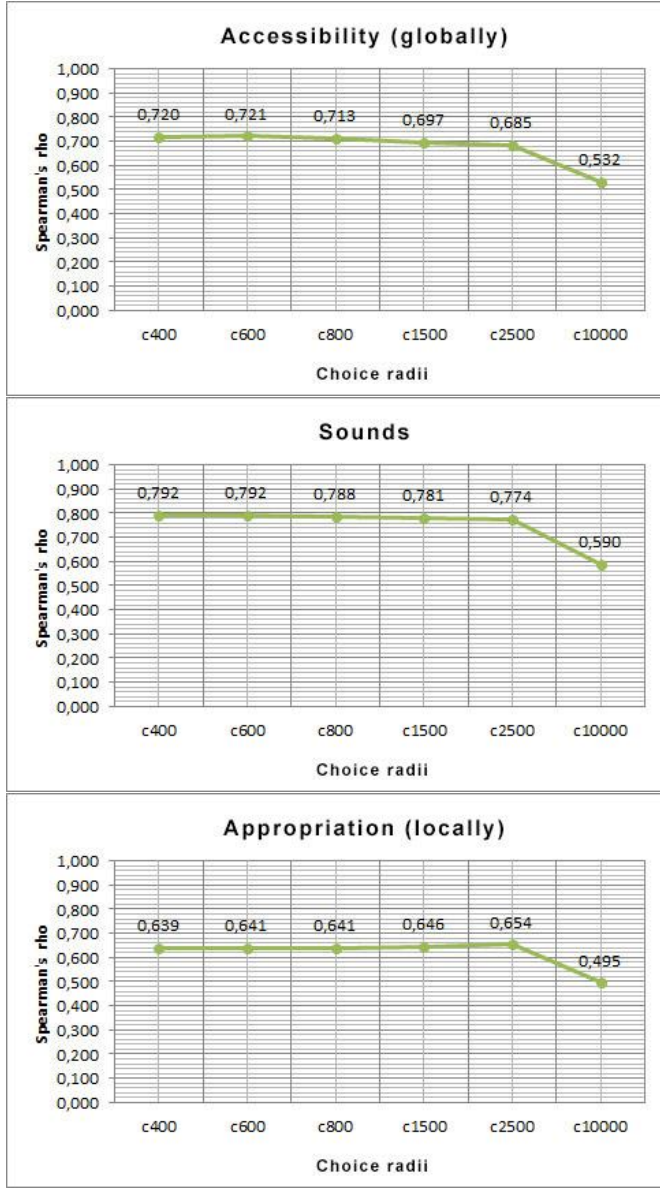

Figure 14 Results, Spearman's correlation coeficient, questionnaire variables - choice measure for different application radii

\section{CONCLUSIONS}

In such times when modern mega-cities are constantly expanding their boundaries, complex relationships and flows are developing within them. Globalized economic and political relations, the infinity of information dissemination and the impersonality of today's communication affect both, on a global and on a local scale. The transformations that take place can be found in the daily lives of the mega-city dwellers, in the way they move and interact with the city as an entity. In this context, it is appropriate to examine the perceived form of this relationship, as well as the experience generated by this interaction between the users of the city and the city itself. 
As it is difficult to examine a metropolis such as Athens as a whole, this research is focused on one district, Akadimia Platonos, a neighborhood in the west part of the center of Athens. Akadimia Platonos neighborhood is an area that has unique characteristics, in other words, a special physiognomy. The area has a variety of uses and forms as well as a wide dissemination of functions (productive activities, housing and cultural uses). It is characterized by three distinct sub-regions with significant spatial and functional variations: the residential area, its craft park area (BIO.PA) and the archaeological grove of Plato's Academy.

The objective of this paper is to establish a methodological framework, in order to be able to perform a spatial analysis of everyday life experiences enriching a socio-spatial approach, contributing in understanding the society in modern cities. Therefore, the study on its core focuses on investigating the association, convergence, and divergence between perceived space and what is actually lived within the boundaries of the Akadimia Platonos neighborhood, applying the social theory of space as expressed by Henry Lefebure, that is, a tripartite dialectic between spatial practices (perceived space), representations of space and representational spaces (lived space). Spatial practices, which incorporate a close correlation within the perceived space, between the daily routine and the routes and networks connecting the places intended for work, "private" life and leisure, were approached through a space syntax analysis of the area. In particular, the integration and choice measures for different application radii were calculated. As for the representational spaces -the lived space- the space of the residents and the body-produced space in daily practices, the releuant information was obtained through direct contact with the users of the neighborhood through a questionnaire. The questionnaire examined the development of social relationships, the conservation of an individual-collective memory, accessibility, walkability, abandonment, the sensory qualities of olfactory and acoustic stimuli, the corresponding nuisance they cause and the level of appropriation the users experience, both for the exact place where the respondent completes the questionnaire as for the whole district.

In this direction, a key concern of our research was the development of a methodological framework according to which the data collected on perception (space syntax analysis) and experience (spatial analysis of questionnaire results) would be analyzed on a common basis, making the production of findings possible.

- After applying this methodological framework, implemented in a GIS environment, the main aim of this work was achieved. Using the Spearman's rho correlation coefficient, the two datasets appeared to be positively correlated with fairly good correlation values, ranging from 0.56 to 0.81 for the correlation of the categorical data with the measure of integration, and in the range of 0.49-0.79 for the measure of choice. As a general conclusion, a particular reduction of the correlation level can be reported when the analysis refers to the global scale for both syntactic measures. When the analysis is removed from pedestrian movement (local scale, $200 \mathrm{~m}-800 \mathrm{~m}$ analysis) and begins to refer to vehicle movement (global scale, greater than $1500 \mathrm{~m}$ analysis) within the urban fabric, both syntactic accessibility (integration) and syntactic capability of passing-by (choice), which are measures of perceived space, gradually lose the ability to correspond to the manifestations of the space as assigned in the questionnaire (socio-community, sensory-physical experience, functional-spatial) and captured in the experience of the users of the neighborhood's area. 
- Regarding the questionnaire data, it is worth mentioning the very good response of the data collected on the sensory quality of sound and nuisance caused by city sounds, both in terms of integration and choice (0.63 -0.81 for integration, 0.590.79 for choice, with almost all of the correlation records related to the choice measure obtaining values above 0.77). Places that are easily accessible or constitute a pedestrian crossing option, in general, do not generate a particular noise disturbance to the users of these sites. A condition that is sharply reversed, but not fully (ordinary city dwellers are used to vehicle sounds), as the range of application of the measures increases and relates to vehicle movement. It is logical that the most accessible and crossing option spaces for driving within a city are the avenues and highways, being capable of carrying large amounts of traffic and, as a result, generating around them a particular nuisance due to noise in the context of urban tissue.

- Apart from the data on the sounds of the city, there is a particularly positive correlation with both integration and choice in regard to the walkability of the neighborhood as experienced by its users. The areas of the neighborhood chosen to be walked through are those that are perceived as accessible and being crossing options.

- The data of another element, for which only the positive correlation with the measure of choice deserves special mention, the measure of integration staying average, is that collected on the sensory quality of the smell in the neighborhood. Places that are considered accessible by those present in the area, are those with the lowest nuisance level.

- On the other hand, a positive but not strong correlation is found between the neighborhood's syntactic structure model and the appropriation experienced by the users of the Akadimia Platonos neighborhood (ualues 0.57-0.68 for integration, 0.49-0.65 for choice).

- The correlation of the data concerning the points of the neighborhood that are characterized by strong abandonment shows similar, relatively low rates.

It becomes clear then that, to some extent, the analysis of the syntactic structure model, which is an analysis of perceived space, follows the tendencies of the analysis of space as experienced by the users, it is not though identical with the later.

\section{FURTHER RESEARCH}

Knowledge and understanding of society is the only way to protect the environment and safeguard the future of cities (Mougiakou \& Photis, 2014; Bartzokas-Tsiompras \& Photis, 2019, 2020b, Bartzokas-Tsiompras et al. 2020a). The present work proposes a methodological framework in order to examine the interaction between a city's community and the city itself, to investigate the way the users of a city experience everyday life during constant urban developments. New urban developments are necessary to achieve new general systems that the city demands (González \& Lázaro, 2011), but they must be based on the demands of those who directly experience them. Development decisions affect many of the fields that touch people's everyday lives (González González, 2017). In a context like this the proposed methods hold out many and varied possibilities for the future. Enriching a socio-spatial analysis (through space 
syntax theory) with primary data by contacting directly the community can lead to new perspectives on decision making systems, contributing to the construction of innovative possibilities on spatial planning and design. At the same time, a participatory way of retrieving spatial information was raised, involving community to the first stages of planning processes, bridging the gap between how development is defined by the scientific community and the way it is perceived by people through their daily experiences.

\section{ACKNOWLEDGEMENTS}

The described study was carried out as part of a thesis for the interdisciplinary program of postgraduate studies "Environment and Development" at the National Technical University of Athens (NTUA.

\section{REFERENCES}

Al Sayed, K. (2014). Space Syntax Methodology. London: Bartlett School of Architecture, UCL.

Bartzokas-Tsiompras, A., \& Photis, Y. N. (2017). What matters when it comes to "Walk and the city"? Defining a weighted GIS-based walkability index. Transportation Research Procedia, 24, 523-530. https://doi.org/10.1016/j.trpro.2017.06.001

Bartzokas-Tsiompras, A., \& Photis, Y. N. (2019). Measuring rapid transit accessibility and equity in migrant communities across 17 European cities. International Journal of Transport Development and Integration, 3(3), 245-258. https://doi.org/10.2495/TDI-V3-N3-245-258

Bartzokas-Tsiompras, A., Paraskevopoulos, Y., Sfakaki, A., \& Photis, Y. N. (2021a). Addressing Street Network Accessibility Inequities for Wheelchair Users in Fifteen European City Centers. Advances in Mobility-as-a-Service Systems, 1278, 10221031. https://doi.org/10.1007/978-3-030-61075-3_98

Bartzokas-Tsiompras, A., Photis, Y. N., Tsagkis, P., \& Panagiotopoulos, G. (2021b). Microscale walkability indicators for fifty-nine European central urban areas: An open-access tabular dataset and a geospatial web-based platform. Data in Brief, 36, 107048. https://doi.org/10.1016/j.dib.2021.107048

Bartzokas-Tsiompras, A., \& Photis, Y. N. (2020b). Does neighborhood walkability affect ethnic diversity in Berlin? Insights from a spatial modeling approach. European Journal of Geography, 11(1), 163-187. https://doi.org/10.48088/ejg.a.bar.11.1.163.187

Bartzokas-Tsiompras, A., Tampouraki, E. M., \& Photis, Y. N. (2020). Is walkability equally distributed among downtowners? Evaluating the pedestrian streetscapes of eight European capitals using a micro-scale audit approach. International Journal of Transport Development and Integration, 4(1), 75-92. https://doi.org/10.2495/TDIV4-N1-75-92 
Czerkauer-Yamu, C., \& Voigt, A. (2011). Strategic Planning and Design with Space Syntax. eCAADe Conference, (pp. 125-133). Ljubljana.

De Smith, M. J., Goodchild, F. M., \& Longley, P. A. (2007). Geospatial Analysis. Leicester: The Winchelsea Press.

Escudero, C. A. (2017). The City from Complex System Theories. An Approach to the Study of Malaga Urban Area. European Journal of Geography, 7(5), 162-174.

Gil, J. (2015). Space Syntax Toolkit for QGIS. Users Guide. London, United Kindom: Space Syntax Laboratory, The Bartlett School of Architecture, UCL.

González, M. J. (2017). Planning, Urban Sprawl and Spatial Thinking. European Journal of Geography, 8(1), 32-43.

González, M. J., \& Lázaro, M. L. (2011). Urban Development and Sustainability. European Journal of Geography, 2, 1-12.

Hillier, B., \& lida, S. (2005). Network and Psychological Effects in Urban Movement. COSIT'05 Proceedings of the 2005 international conference on Spatial Information Theory (pp. 475-490). New York: Springer-Verlag.

Hillier, B., \& Vaughan, L. (2007). The City as One Thing. Progress in Planning 67 (3), 205230.

Hofmann, R. (2014). Narrating Spaces. Innouative Entries to (School) Geography. European Journal of Geography, 5(1), 70-80.

Kitsiou, D. (2010). Course Notes "Geographic Information Systems". Mytilene, Lesbos, Greece: Department of Marine Sciences, School of the Environment, University of the Aegean.

Lefebure, H. (1973). La Survie du capitalisme: La reproduction des rapports de production. (B. Frank, Trans.) Paris: Anthropos.

Lefebure, H. (1974). La production de l'espace. (D. Nicholson-Smith, Trans.) Paris: Anthropos.

Lefebure, H. (1977). De l'État-3: Le mode de production étatique. Paris: Union Générale d'Éditions.

Longley, P. A., Goodchild, M. F., Maguire, D. J., \& Rhind, D. W. (2005). Geographic Information Systems and Science. West Sussex: John Wiley \& Sons.

Lykogianni, R. (2011). An account of Lefebure's work. Radical Geography Seminars. Athens: Notebooks of Radical Geography.

Marcus, L. (2007). Spatial Capital and How to Measure It: An Outline of an Analytical Theory of the Social Performativity of Urban Form. 6th International Space Syntax Symposium, (pp. 1-12). Istanbul.

Mohammed, N. (2011). Integration of Social Life with Urban Space Syntax. (M. Wittman, Ed.) Brno, Czech Republic: Brno University of Technology, Faculty of Architecture. 
Mougiakou, E., \& Photis, Y. N. (2014). Urban Green Space Network Eualuation and Planning: Optimizing Accessibility Based on Connectivity and Raster GIS Analysis. European Journal of Geography, 5(4), 19-46.

Stauroulaki, G., Marcus, L., Berghauser Pont, M., \& Nilsson, L. C. (2017). Representations of street networks in space syntax: Towards flexible maps and multiple graphs. 11th Space Syntax Symposium, (pp. 174.1-174.16). Lisbon.

Sukhorukou, V. D., \& Gladkiy, Y. N. (2019). Semantic Outlines of Modern Geography. European Journal of Geography, 10(3), 24-32.

Vaughan, L. (2015). Suburban Urbanities: Suburbs and the Life of the High Street. London: UCL Press.

Zúñiga, M., Sebastian, M., González, R., \& Campos, A. (2017). Creating Public Opinion and Developing Spatial Citizenship Through Maps: The Case of Zaragoza, Spain. European Journal of Geography, 8(5), 62-76.

desktop.arcgis. (2016). desktop.arcgis. How Zonal Statistics works: http://desktop.arcgis.com/en/arcmap/10.3/tools/spatial-analyst-toolbox/hhow-zonal-statistics-works.htm (Accessed 2019-10-03).

desktop.arcgis. (2016). desktop.arcgis. How Fuzzy Membership works: http://desktop.arcgis.com/en/arcmap/10.3/tools/spatial-analyst-toolbox/howfuzzy-membership-works.htm (Accessed 2019-10-03).

Space Group UCL. (2016). github.com/SpacegroupUCL. qgis Space Syntax Toolkit: https://github.com/SpaceGroupUCL/qgisSpaceSyntaxToolkit (Accessed 2019-0915).

Varoudis,

T.

(2012).

github.com/varoudis.

depthmapX: https://github.com/varoudis/depthmapX (Accessed 2019-09-15). 